\title{
Ricardo Carpani: arte, gráfica y militancia política
}

Alejandra Viviana Maddoni *

\section{Resumen / Ricardo Carpani: arte, gráfica y militancia política}

La idea central de este ensayo es realizar un recorrido histórico y reflexivo en torno a la obra compuesta por afiches, ilustraciones y volantes del artista plástico argentino Ricardo Carpani que produjo esencialmente a partir de 1960. Como señala su autora, este recorte posee límites frecuentemente caprichosos e imprecisos sobre una producción muy vasta que está signada por una profunda convicción ideológica. En la búsqueda de la identidad latinoamericana, su autora propone que acercarse y recorrer su obra artística puede significar una apropiación - al menos por un momento - de las utopías de entonces, a fin de sostener, dar sentido y actualizar las propias.

\section{Palabras clave}

Arte político - Carpani - identidad - Latinoamérica.

\section{Summary / Ricardo Carpani: art, graphics and political militancy}

The central idea of this essay is to conduct an historical and reflective route around the art work of the argentine artist Ricardo Carpani that is composed by posters, illustrations and flyers produced essentially as of 1960 . As the author pointed up, this cut frequently present capricious and vague limits on a very vast production that is characterized by a deep ideological conviction. In the search of the Latin American identity, the author proposes that to approach and to cross his artistic work can mean an appropriation - at least for a moment - of past utopias, in order to maintain, to give sense and to update the own ones.

\section{Key words}

Carpani - identity - Latin America - political arte.

\section{Resumo / Ricardo Carpani: arte, gráfica e militância política}

A idéia central deste ensáio é realizar um persurso histórico e reflexivo ao redor à obra composta por afiches, ilustrações e volantes do artista plástico argentino Ricardo Carpani que produz essencialmente a partir de 1960. Como assinala a autora, este recorte possui limites frequentemente caprichosos e imprecisos sobre uma produção muito vasta que está signada por uma profunda conviccão ideológica. Na busca da identidade latinoamericana, sua autora propõe que acercar-se e percorrer sua obra artística pode significar uma apropriação - ao menos por um momento - das utopias de então, ao fim de sustentar dar senso e atualizar as próprias

\section{Palavras clave}

Arte politica - Carpani - identidade - Latinoamérica.

\footnotetext{
* Licenciada en Artes Visuales con especialidad en Pintura (IUNA). Profesora Nacional de Pintura (E. Nacional de Bellas Artes Prilidiano Pueyrredón). Docente universitaria y Prosecretaria Técnica de la Secretaría de Cultura de la Facultad de Bellas Artes de la Universidad Nacional de La Plata.
} 
Hacer un recorrido histórico y reflexivo en torno a los afiches, ilustraciones y volantes que el artista plástico argentino Ricardo Carpani produjo, esencialmente a partir de 1960, significa generar un recorte con límites frecuentemente caprichosos e imprecisos sobre una producción vastísima siempre signada por una profunda convicción ideológica.

Carpani fue uno de los artistas fundadores del grupo Espartaco que comenzó a funcionar ogránicamente a partir de 1959. Junto a él, Juan Manuel Sanchez, Mario Mollari, Pascual Di Bianco, Esperilio Bute, Carlos Sessano y Juana Elena Diz, entre otros, sostenían: "A todos nos une la misma comprensión: contribuir a que el sujeto vea a través del arte lo que el sistema le oculta".

Con la redacción del manifiesto, formalizaron una herramienta de análisis social y político poniendo a disposición estrategias y recursos plásticos con los que intervenir activamente en la realidad nacional. Este instrumento no se constituyó bajo la forma de credo ni dogma estético, dando libertad de acción en el uso de técnicas, materiales y elementos plásticos, siempre que estuvieran en función de un contenido trascendental que colocara en un primer plano al sujeto histórico, las mayorías populares y la construcción de la "Gran Nación Latinoamericana".

Señalando la pintura de caballete como género burgués y solitario destinado a unos pocos, sus pinturas de grandes dimensiones hacían gala de un expresionismo social con una fuerte impronta americanista. Sus enormes figuras escultóricas subordinaban el color al tema y al dibujo a través de paletas reducidas o monocromáticas y de valores bajos. Mientras Carpani, Di Bianco y Sánchez hacían centro en la problemática del trabajador urbano, Mollari profundiza en la realidad del campesino e indígena.

\section{Arte y proletariado}

(...) El orden establecido tiende más bien a alejar al pueblo de las manifestaciones del espíritu, dándole en su reemplazo y en cantidades crecientes, productos embrutecedores, neutralizantes de su sensibilidad. Se hace así del arte lujoso vicio solitario, reservado a determinadas élites de iniciados, alejándolo de su verdadera misión. Si la solución de este problema no vendrá del lado de la burguesía, interesada en manenerlo y agudizarlo, debe ser la clase obrera organizada quien tome la iniciativa, bindando las paredes de los sindicatos y las páginas de sus publicaciones para que, a través de ellas, puedan los artistas expresar libremente y sin trabas su mensaje de estímulo revolucionario. Compréndase que existiendo identidad de intereses entre el artista revolucionario y el obrero consciente, y rigiéndose ambos por los mismos valores, el único impedimento que existe para su comunicación mediante la obra, es la infrecuencia del contacto. Deben, por lo tanto, los círculos directivos del proletariado, resolver este conflicto, ya que constituye una parte considerable de la lucha revolucionaria.

El arte por su relación dialéctica sobre la realidad, acelerando el proceso de cambio, por la profundidad de su mensaje, cpaz de llegar a zonas del ser humano donde no llegan las ideas, por su poder estimulante sobre las masas y su valor propagandístico, es un arma de inapreciable importancia, cuya desestimación sólo favorece a quienes tienen interés en mantenerlo al margen de la lucha de clases: la burguesía y el imperialismo. (Carpani, R., 1960) (1)
A pesar de la escasísima tradición mural de nuestro país, el grupo retomó uno de los propósitos de Siqueiros ${ }^{(2)}$ durante su visita a nuestro país: la exaltación del arte mural como expresión monumental y pública del arte revolucionario y como presencia activa en la cotidianeidad del pueblo latinoamericano.

En un texto a la manera de proclama publicado por el diario Crítica el 2 de junio de 1933, el artista mexicano realizó la siguiente convocatoria:

\section{Un llamamiento a los plásticos argentinos}

Pintores y escultores estamos trabajando para crear en la Argentina y en el Uruguay (quizás en toda la América del Sur) las bases de un movimiento de la plástica monumental descubierta y multiejemplar para las grandes masas populares.

Pretendemos sacar la obra plástica de las sacristías aristocráticas, en donde se pudre hace más de cuatro siglos.

Nuestros campos de operaciones serán aquellos lugares en que concurren mayores núcleos de personas y aquellos en que el tráfico del pueblo sea más intenso.

Usaremos los procedimientos que permitan darle a nuestras obras más amplia divulgación.

Vamos, pues, a producir en los muros más visibles de los costados descubiertos de los altos edificios modernos, en los lugares más estratégicos plásticamente de los barrios obreros, en las casas sindicales, frente a las plazas públicas y en los estadios deportivos y teatros al aire libre.

Vamos a sacar la producción pictórica y escultórica de los museos - cementerios-y de las manos privadas para hacer de ellas un elemento de máximo servicio público y un bien colectivo, útil para la cultura de las grandes masas populares.

Vamos a romper el estrecho círculo mortal de la pintura de caballete, para penetrar valientemente en el campo inmenso de la pintura multiejemplar.

Vamos a sacar la escultura del absurdo del taller y del banco giratorio, para restituirla policromada a la arquitectura y la calle. Vamos a libertar la pintura y la escultura de la escolástica seca, del academismo y del cerebralismo solitario del artepurismo, para llevarlas a la tremenda realidad social que nos circunda y ya nos hiere de frente.

Vamos a restituir a la plástica el único sistema posible para su enseñanza, que consiste en la aplicación del principio invariable de que no se puede enseñar a pintar, a esculpir, a grabar, más que haciendo participar al aprendiz en el proceso total de la obra en desarrollo y ligando a los hechos diarios y concretos de ese desarrollo las enseñanzas teóricas correspondientes.

Vamos a sacar a la plástica del miserable intento individual, para retornarla al procedimiento colectivo racional y democrático usado por los talleres corporativos de las épocas florecientes del arte.Trabajaremos en teams o en equipos, perfeccionando cada día más la coordinación de nuestras individualidades, en relación directa con la capacidad de cada uno, como lo hacen los buenos jugadores de foot ball. En esa forma, nuestras obras periódicas constituirán la única y formidable escuela pública de las artes plásticas.

Vamos a terminar con los objetos estáticos y mezquinamente circuscritos a modelos personales descriptibles, las escenas y objetos pueriles, para llegar hasta los nuevos elementos que nos ofrecen las férreas anatomías de las máquinas en movimiento, el relámpago deportivo con sus grandes espectáculos de masas y las ascendentes batallas sociales en la más exasperada y tremenda pugna que recuerda la historia del mundo.

Vamos a salir de la penumbra plácida del atelier y escuelas montparnasianas para caminar por la plena luz de las realidades 
humanas y sociales de las fábricas, de las calles, de los barrios obreros, de las carreteras y del campo enorme con sus chacras y sus estancias.

Vamos a beber en las fuentes vivas de los hechos diarios la convicción que sirva de motor impetuoso a nuestra obra, concientes de que fue la convicción cristiana (un ejemplo solo) el dínamo que hizo brotar el inmenso arte popular de las primeras y más ejemplares épocas del renacimento italiano.

Nos preocupamos particularmente por encontrar las herramientas y materiales consecuentes con la naturaleza tremenda de la obra que emprendemos.

Buscaremos la forma que corresponda al contenido de nuestra expresión plástica. Para nuestro intento contamos ya con dos grandes antecedentes, con dos magníficas experiencias, que nos dan los conocimientos iniciales del oficio de esta nueva y maravillosa profesión nuestra. Me refiero al experimento primario que representa el renacimiento mexicano, ya en proceso de liquidación, y a la experiencia más integral, más moderna, iniciada por el bloque de los pintores de Los Angeles, California, y en pleno proceso actual de desarrollo y perfeccionamiento. El primero nos da las bases fundamentales al establecer el principio de la supremacía de la pintura monumental (interior) sobre la pintura de caballete. Nos muestra la necesidad de ligar la obra moderna con las grandes tradiciones americanas. Nos da el conocimineto objetivo de los procedimientos de la pintura monumental tradicional, perdidos con la terminación del renacimiento italiano. Nos muestra, por último, que las obras maestras de todos los tiempos han sido fruto de convicciones sociales.

El segundo (el del bloque de pintores) afirma los principios y métodos conservables del renacimiento mexicano, mostrándonos su verdadera naturaleza de esfuerzo inicial, con todas sus equivocaciones y fallas. Nos abre la puerta de par en par al mundo nuevo de la técnica moderna, suceptible de ser utilizada para la producción plástica. Nos da por primera vez en el mundo los vehículos objetivos y subjetivos que exige la gran pintura mural descubierta y multiejemplar para las masas, que vivirá bajo el sol, bajo la lluvia, frente a la calle, en el primer caso, y en todos lo hogares proletarios en lo que al segundo se refiere. Nos muestra el uso del cemento en vez de la mezcla de cal y arena del fresco tradicional, ya inaplicable a las condiciones de la edificación moderna. Nos muestra el uso de la brocha mecánica, de la compresora de aire, del borrador de arena, etc. Nos inicia en el uso de las corrientes eléctricas para la coloración de los muros por diferentes grados de cristalización. Nos muestra la técnica del trabajo colectivo. Nos enseña la composición dinámica que exige la plástica descubierta. La experiencia del bloque de Los Angeles, California, nos da, en una palabra, todo lo que necesitamos para producir plástica de las masas y para las grandes masas humanas.

Pero todo este programa sería irrealizable si no procediéramos en su aplicación de manera orgánica. Eso es lo que hará el Sindicato de Artistas Plásticos, de reciente fundación, en este medio.

Es pues urgente que todos los productores de plásticas, comprensivos de la veracidad de nuestros principios, se apresten, desde ya, a sumarse a sus filas.

Hacia 1961, Carpani y Di Bianco se separaron del grupo para insertarse de lleno en el movimiento obrero, realizando trabajos en las muros de algunos gremios como los murales del Salón de Actos del Sindicato de Obreros de la Industria de la Alimentación, Sanidad y Vestido. ${ }^{(3)}$
En efecto, una de las principales preocupaciones del Carpani artista y militante giraba en torno a crear una imagen que se acercara a la gente, al trabajador, cuando ellos necesitaran de ese estímulo artístico. El desafío era encontrar los medios más efectivos para poder comunicar a través de esa imagen; ideas y sensaciones que transformaran la realidad -su realidad social- con el máximo de calidad estética, rigurosidad formal y profundidad significativa. Sin necesidad de apelar a convencionalismos publicitarios, su imagen artística de aquellos años sigue siendo aún hoy, ícono de trabajadores y militantes al momento de expresar sus resistencias y luchas.

Sin lugar a dudas es por esto último que la obra gráfica de Carpani trasciende su compromiso militante y la eficacia icónica con la que supo dar respuesta a la realidad social de entonces para presentarse hoy como un conjunto artístico de insoslayable actualidad y con peso propio.

El modo de reproducción de afiches, ilustraciones y panfletos terminó de sellar el objetivo de máxima: acercar y generar un vínculo indisoluble entre artista y multitudes sociales. En este sentido se confirmaba, en parte, lo que Benjamin afirmaba acerca de la técnica reproductiva: desvincula lo reproducido del ámbito de la tradición imponiendo la presencia masiva de las copias en el lugar de una presencia irrepetible y actualizando lo reproducido al permitirle salir al encuentro de cada destinatario. ${ }^{(4)}$

La ilustración de poemas y textos en libros, revistas y diarios lograron una difusión de la imagen de Carpani más bien restringida. Cuando la CGT reorganizada luego de la dictadura militar le encargó con motivo de la "Semana de Protesta" (1962) el afiche ¡basta! su hombre trabajador agigantado, fortalecido por la sociedad en la que se encuentra inmerso; adquiere difusión masiva a nivel nacional.

El semanario Compañero tituló Un afiche histórico un artículo donde describe que:

(...) por primera vez se nos entrega una imagen tan combativa, tan abrupta, tan decidida de los trabajadores. Por primera vez también, un muralista participa en estas labores.... puede marcar el comienzo de una época de colaboración entre el pueblo y los artistas. ${ }^{(5)}$

\section{Reflexiona Ernesto Laclau: ${ }^{6)}$}

Carpani, hombre de gran lucidez, en función de estos datos elaboró su táctica sin abandonar su estrategia muralista. Y ella se concretó en la gráfica política: cartelones para actos, imágenes para volantes y periódicos y afiches callejeros. Su "hombre" todo músculo nos refiere directamente al trabajo y a la lucha... Es la jerarquización del hombre en lucha. Pero por ello mismo valió como un logotipo de rebeldía revolucionaria.

El de Carpani no es un hombre derrotado, triste e impotente ante la realidad. Es el trabajador contundente, activo, movilizado, que lucha por la justicia. Se constituye en el ideal que rebasa las fronteras de nuestro país para ponerse al servicio de Latinoamérica toda.

Si bien Carpani era conciente que el arte no podía -ni debía- resolver los problemas de dependencia política, sí creía firmemente en que la obra podía generar fuertes procesos de identificación nacional y latinoamericana. Esta postura le valió -tanto a él como a Pascual Di Bianco-, el silencio de la prensa y la crítica: "Bastó, en efecto, que ambos pintores unieran sus creaciones a los 
intereses de las masas proletarias para que una lápida cayese sobre ellos" reflexionaba Hernández Arregui en el semanario Compañero en agosto de 1963.

(...) Yo no creo en ese arte de miseria, llorón, que pinta la tragedia por la tragedia de los trabajadores y del pueblo. Yo prefiero ver los aspectos positivos, dinámicos. No es la miseria, sino la voluntad de lucha, la voluntad de llegar a ser seres humanos. (Carpani, R., 1982) ${ }^{17}$

La originalidad y eficacia de sus carteles en la vía pública eran contundentes: los porteños se detenían a discutir el significado de esas imágenes tan poco usuales, su raíz política, su mensaje. No faltaba el que intentaba con afectuoso cuidado, despegar el afiche para llevarlo a su hogar. Había logrado lo que muy pocos: que el destinatario, el pueblo, la clase obrera, hiciera suya su obra.

Lo interesante de observar fue la reacción positiva de las masas frente a un tipo de imagen al cual no estaban en absoluto habituadas y su identificación emocional con ella en función de la emotividad combativa imperante en esos momentos, pues yo no hice ninguna concesión del tipo naturalista en esos afiches y me expresé libremente manteniendo todas las distorsiones, deformaciones y estilizaciones propias de mi personal visión artística de la realidad.

Mucha gente, estudiantes, obreros, despegaban los afiches mientras aún estaban frescos para llevárselos. Años después me encontré con algunos de estos afiches decorando las paredes de hogares obreros. ${ }^{(8)}$

Lo novedoso residía en el hecho que eran afiches ilustrados por un artista que tomó partido por una actitud superadora frente a la creación: sin renunciar a la singularidad de su lenguaje, experimentó formal y estéticamente hasta lograr una imagen plástica expresiva, comunicativa e imbricada con la realidad social de entonces. Su imagen se fue "amasando" a través de su relación con los trabajadores y su militancia. Hasta entonces, los carteles del movimiento obrero aparecían con ilustraciones convencionales de dibujantes publicitarios cuya articulación ideológica con la causa era nula.

El vínculo del artista con el movimiento sindical se afirma y aparecen, entre otros, los afiches por la desaparición de Felipe Vallese ${ }^{(9)}$, primer desaparecido de la historia argentina contemporánea y sobre la desocupación. El posterior y progresivo apoyo del vandorismo de la CGT al golpe de Onganía; lo aleja de la Confederación

Formó parte del grupo CONDOR creado por Hernández Arregui. Este proyecto nació con un afiche de su autoría con la imagen de Felipe Varela ${ }^{(10)}$. Ortega Peña, Eduardo Duhalde, Bellóni y Bortnik, entre otros, se proponen producir un acercamiento entre el marxismo y el peronismo vía desarrollos e investigaciones políticos, sociales, economicos y culturales. En un intento por renovar la experiencia de F.O.R.J.A., adoptaban la metodología del marxismo para la investigación de la realidad histórica y como guía de acción política.

Hacia fines de los 60 -entre el 28 y 30 de marzo de 1968-el Congreso Normalizador "Amado OImos" ve nacer a la CGT de los Argentinos. Esta surge como respuesta alternativa y opositora a las conducciones burocráticas de las 62 Organizaciones hegemonizadas por Vandor (UOM). La lidera Raimundo Ongaro de la Federación Gráfica Bonaerense. Integran la dirección de la CGTA La Fraternidad, la Unión Tranviaria Automotor (UTA), los navales, los carboneros, la Federación de Obreros y Empleados de Teléfonos de la República Argentina (FOETRA), Personal Civil de la Nación y la Asociación Trabajadores del Estado (ATE).

"Más vale honra sin sindicatos que sindicatos sin honra" es una de las consignas que intenta reunir en una misma dirección a estudiantes, intelectuales, artistas, empresarios nacionales pequeños y medianos, religiosos y trabajadores; constituyendo como ámbito de encuentro durante más de tres años a la CGTA.

El movimiento obrero no es un edificio ni cien edificios, no es una personería ni cien personerías, no es un sello de goma ni es un comité; no es una comisión delegada ni es un secretariado. El movimiento obrero es la voluntad organizada del pueblo y como tal no se puede clausurar ni intervenir. ${ }^{(11)}$

Carpani se incorpora activamente a este nuevo espacio, desarrollando experiencias de militancia artística junto al Grupo Cine Liberación del que formaban parte, entre otros, Fernando Solanas y Octavio Getino (La Hora de los Hornos, 1966-1968). La aparición de este cine en nuestro país en mucho casos va a requerir un tipo de exhibición clandestina, porque los circuitos de exhibición están obstruidos por un problema de censura política -fundada en el ataque abierto al gobierno militar de turno- y/o comercial. Como los afiches, cartelones e ilustraciones de Carpani, estas películas buscan intervenir directamente en el proceso político y la realidad social. Desde lo cinematográfico estas películas no reciben la autorización del Ente de Calificación Cinematográfica, ni el fomento del Instituto de Cinematografía.

En base a su anterior trabajo mural en sindicatos, a Carpani se le encomienda la realización sistemática de afiches que acompañen cada uno de los reclamos por reivindicaciones sociales, laborales y políticas bajo la forma de movilizaciones, encuentros y huelgas generales. Sus imágenes, menos vinculadas con un realismo social que con un expresionismo monumental, se iban constituyendo como íconos de la resistencia popular y la clase trabajadora. Ellas también acompañaban frecuentemente los textos del periódico que dirigía Rodolfo Walsh e ilustraban láminas de muy buena calidad de impresión que se vendían para juntar fondos.

En la producción gráfica de Carpani el dibujo en tinta -generalmente acromático- domina la composición. El texto y su tipografía (a veces a mano alzada) están más que nunca al servicio de la imagen y subordinada a ella. La línea es el elemento plástico por excelencia que estructura y configura planos cerrados con morfologías orgánicas que se destacan fuertemente del fondo. Pero también es cuidadosa trama que describe distintas situaciones de luz en el espacio plástico.

Aún en los formatos más pequeños correspondientes a cartelería, ilustraciones y láminas, la solidez de sus personajes mantienen la presencia monumental que exhiben en las pinturas murales. Los rostros y especialmente las manos abiertas que guían y conducen o que se tensionan en puños imponentes que resisten y luchan se imponen en los primeros planos de las composiciones. Son las partes de la figura humana privilegiadas por el artista donde despliega su maestría expresiva como dibujante al tiempo que genera centros de interés y ritmos compositivos.

Carpani reconocía en Miguel Ángel una influencia decisiva en lo que refiere a la concepción formal de la figura humana. Con Petorutti como maestro, abordó cuestiones vinculadas con 
aspectos compositivos, cromáticos y técnicos; más ligadas al plano sintáctico de la creación artística. El muralismo latinoamericano como concepto estético y monumental de las formas y compromiso social no sólo intervino en su producción sino que como corriente de artistas, lo incorporó en sus filas.

En la sede de la CGTA realiza una exposición de cartelones murales sobre papel donde las imágenes eran acompañadas por consignas políticas del tipo "Tomar las fábricas". Esta muestra se realiza también en el Instituto Juan Manuel de Rosas de La Plata donde, en horas de la noche, destruyeron las piezas gráficas expuestas. No obstante ello, Carpani juntó y pegó los pedazos y los siguió exponiendo en otros lugares.

En ocasión de la visita de Rockefeller al país, organizó y participó de una muestra de afiches en la SAAP que se llamó Malvenido Rockefeller el 30 de junio de 1969. La exposición tuvo que ser levantada por presión policial y los afiches escondidos.

Con la dictadura militar de 1976, la mayor parte de la obra gráfica de Carpani fue quemada, escondida o silenciada. Dejó de circular. No obstante, el artista desde el exilio siguió haciendo afiches para organismos de derechos humanos, y comités de apoyo a Nicaragua y El Salvador.

(...) Podría decirse que el arte es utopía pura porque uno está creando mundos. Y en esos nuevos mundos depositamos nuestras ilusiones. Depositamos nuestras utopías en las obras que crean nuevos mundos. Y así le damos vigencia a esas utopías, vigencia social.

En este sentido pienso que sí, en determinadas épocas, el último refugio que le queda a las utopías es el de la creación artística. ${ }^{(12)}$

Respecto al período artístico post-exilio el ensayista Manuel Vicent reflexionaba: "En vista del desastre general de la historia, Ricardo Carpani se ha llevado a todas sus criaturas a la jungla y en compañía de sus sueños ha oficiado con ellas un banquete surrealista para celebrar el fin de la utopía". Sinceramente cuesta trabajo imaginar a Carpani festejando el fin de alguna utopía. En todo caso, hubiera dejado de crearles esos enormes y soberbios refugios.

Acercarse y recorrer su obra artística puede significar apropiarnos -al menos por un momento- de sus utopías de entonces, a fin de sostener, dar sentido y actualizar las propias.

En algún lugar sin tiempo ni urgencias hace ya diez años que Ricardo Carpani nos sigue regalando otros mundos posibles.

\section{Notas}

1 En Arte y Política en los '60. (2002). Catálogo de muestra en Palais de Glace, Buenos Aires: Fundación Banco Ciudad.

2 David Alfaro Siqueiros (1896-1974), pintor muralista mexicano, visitó nuestro país en 1933. En esa ocasión reunió un equipo de trabajo con el que experimentó nuevas técnicas y procedimientos para llevar a cabo el trabajo mural "Ejercicio Plástico" en el sótano de la quinta de Natalio Botana.

Los desacuerdos entre los artistas argentinos -especialmente Berni- y Siqueiros acerca de los objetivos y contenidos del arte mural, más una realidad política argentina decididamente distinta a la mexicana o brasileña donde el Estado estimulaba la creación mural y organizaba el espacio público en línea con este objetivo; redujo esta expresión a unas pocas manifestaciones públicas con temáticas más bien convencionales.

3 Seis paneles del Sindicato de Obreros de la Alimentación aún se conservan en buen estado, el resto de la producción mural se encuentra muy deteriorada o destruida.

4 Benjamin, W. (1936). La obra de arte en la época de su reproductibilidad técnica.

5 Referido en Arte y política en los '60, op.cit.

6 Laclau, E. y Noe, F. (1994). Carpani. Gráfica Política, Buenos Aires: Ediciones AYER.

7 Entrevista a Ricardo Carpani. (1982). Suplemento Arte y Educación. Diario Hoy, Quito. Ecuador.

8 Entrevista a Carpani. Documenta. 1971/72

9 Felipe Vallese, obrero metalúrgico y delegado de la fábrica TEA era un joven militante de 22 años de la resistencia peronista. El 23 de agosto de 1962 a las 23.30 fue secuestrado junto a un grupo de militantes en Flores Norte, en Canalejas 1776 (hoy Felipe Vallese). Varios hombres armados lo golpearon y llevaron. Se estima que murió durante los interrogatorios y su cuerpo fue ocultado. Nunca apareció. Fuente: Alejandro Incháurregu, fundador del Equipo Argentino de Antropología Forense.

10 Felipe Varela (1821-1870) fue un caudillo andino nacido en Catamarca. Condujo las montoneras de la década de 1860. A principios de la década de 1840 Varela lucha contra Rosas. Fue a Chile, en donde se incorporó al ejército chileno; luego de la caída de Rosas en 1852, regresó a la Argentina y se unió al ejército de la Confederación; luchó bajo las órdenes de Urquiza en Pavón; en 1862, se unió al Chacho Peñalosa en su sublevación contra las autoridades nacionales de Buenos Aires.

Se suele considerar a Varela un líder político -el último del grupo de Artigas, Ramírez, Quiroga, Chacho Peñaloza, quienes se opusieron a que la organización política de la Nación se hiciera desde la Capital Federal en Buenos Aires.

11 Ricardo Carpani. (1973). Palabras iniciales. Semanario de la CGTA.

12 Entrevista de Estaban lerardo a Ricardo Carpani publicada en la desaparecida revista Reencuentro.

\section{Bibliografía}

- Benjamin, W. (1936). La obra de arte en la época de su reproductibilidad técnica.

Linares, S. Ricardo Carpani. La estética combatiente, Caminos del arte: SAAP.

- Carpani, R. (1973). Palabras Iniciales. Semanario de la CGTA.

- Giunta, A. (2001). Vanguardia, internacionalismo y política. Arte argentino en los años sesenta. Espacios del saber Nro. 22. Paidós.

- Laclau, E. y Noé, L. F. (1994). Carpani. Gráfica Política. Ediciones Ayer.

- Cipollini, R. (2003). Manifiestos argentinos. Edición Crítica. Políticas de lo visual. 1900-2000. Adriana Hidalgo Editora.

Arte y política en los '60. (2002). Catálogo de muestra en Palais de Glace, Buenos Aires. Fundación Banco Ciudad.

- Brownstone, G. (1989). Entrevista a Carpani. París, Documenta. 1971/2. Tabaré. "Ricardo Carpani. El artista militante". Vidas con historia. Sur. 